\title{
Relationship between walking performance and types of community-based activities in people with stroke: an observational study*
}

\section{Relação entre desempenho da marcha e tipos de atividades na comunidade após acidente vascular encefálico}

Matar Alzahrani, Catherine Dean, Louise Ada

\begin{abstract}
Objectives: To examine the relationship between clinical walking performance and amount and type of community activity in people after stroke. Methods: A cross-sectional observational study of 14 people with stroke living in Sydney and able to walk was carried out. Demographics (such as age, gender, side of stroke, time since stroke, presence of spouse) and aspects of walking performance (such as speed, capacity, automaticity, and stairs ability) were measured. People with stroke were observed for at least five hours while they carried out activities in the community. These activities were then categorized into four types: domestic intrinsic, domestic extrinsic, leisure without contact, and leisure with contact activity. Results: No relationship was found between walking performance and the amount of community activity. There was no relationship between walking performance and total time spent on domestic intrinsic activity. Walking speed and stairs ability were significantly correlated with leisure with contact activity $(r=0.56, p=0.04$, and $r=0.57$, $p=0.03$ respectively) and inversely correlated with leisure without contact $(r=-0.72, p<0.01$, and $r=-0.66, p=0.01$ respectively $)$. Walking capacity was also inversely correlated with leisure without contact $(r=-0.77, p<0.01)$. Only stairs ability was significantly correlated with domestic extrinsic activity $(r=0.77, p<0.01)$. Conclusions: Findings suggest that if walking performance is poor after stroke, activities at home and in the community will be limited, so that people may become housebound and isolated from society.
\end{abstract}

Key-words: walking; activities of daily living; stroke; observation.

\section{Resumo}

Objetivos: Examinar a relação entre o desempenho da marcha e a quantidade e tipo de atividades na comunidade em indivíduos após acidente vascular encefálico (AVE). Métodos: Realizou-se um estudo observacional transversal em 14 indivíduos com AVE, aptos a deambular, residentes em Sydney. Resultados demográficos (como idade, gênero, lado hemiparético, tempo desde o AVE, estado civil) e aspectos de desempenho da marcha (como velocidade, resistência, automaticidade e habilidade de usar escadas) foram avaliados. Os indivíduos foram observados por pelo menos cinco horas durante suas atividades na comunidade. Essas atividades foram então categorizadas em quatro tipos: intrínseco-doméstica, extrínseco-doméstica, atividade de lazer com contato e atividade de lazer sem contato. Resultados: Nenhuma relação foi encontrada entre desempenho da marcha e quantidade de atividades na comunidade. Também não houve relação entre desempenho da marcha e tempo gasto em atividade intríseco-doméstica. Velocidade da marcha e habilidade no uso de escadas correlacionaram-se significativamente com atividade de lazer com contato ( $r=0,56, p=0,04$ e $r=0,57$, $p=0,03$, respectivamente) e correlacionaram-se inversamente com atividade de lazer sem contato $(r=-0,72, p<0,01, e r=-0,66, p=0,01$, respectivamente). Desempenho da marcha correlacionou-se inversamente com atividade de lazer sem contato $(r=-0,77, p<0,01)$. Apenas habilidade no uso de escadas correlacionou-se significativamente com atividade extrínseco-doméstica ( $r=0,77, p<0,01)$. Conclusões: Os resultados sugerem que se o desempenho da marcha fica comprometido após o AVE, as atividades em casa e na comunidade serão limitadas e, com isso, os indivíduos podem se tornar confinados à casa e isolados da sociedade.

Palavras-chave: marcha; atividades de vida diária; AVE; observação.

Received: 03/02/2010 - Revised: 07/07/2010 - Accepted: 01/10/2010

Physical Therapy Department, The University of Sydney, Sydney, NSW, Australia

* This work has been presented as a poster presentation at The University of Sydney 6"th Biennial Health Research Conference "From Cell to Society 6" (FCTS6), which was held in Leura, NSW, Australia, on $11^{\text {th }}-12^{\text {th }}$ November 2008.

Correspondence to: Catherine Dean, Faculty of Health Sciences, The University of Sydney, PO BOX 170, Lidcombe, 1825, NSW, Austrália, e-mail: catherine.dean@sydney.edu.au 


\section{Introduction $: \therefore$.}

The goal of rehabilitation after stroke is to optimize function and encourage participation and independence in the community ${ }^{1}$. However, approximately $50 \%$ of people with stroke remain dependent on others for some activities ${ }^{2}$. Despite the fact that many people with stroke regain independence in basic activities such as showering, dressing, and mobility, less people become independent in performing more complex activities such as household chores, shopping, leisure, and social outings, which are essential for full participation in the community. Carod-Artal et al. ${ }^{3}$ found that $48 \%$ of their sample were still restricted to basic activities, $30 \%$ did not perform any household chores, $15 \%$ did not undertake either outdoor mobility activities or social outings, and $63 \%$ did not engage in any hobby.

Community participation is not solely a matter of physical activity. It also includes leisure activities and social interaction. Recently, De Wit et al. ${ }^{4}$ developed a valid and reliable list to define everyday activities by the type of activity. They categorized activities into personal activities of daily living (washing, toileting, eating, etc), domestic activities of daily living (washing up, ironing, cleaning, etc.) and leisure- and work-related activities (office and computer work, socializing, printing, painting, etc.), that is, activities were categorized to give insight into the type of participation in the community. However, the different types of everyday activities may indirectly depend on physical ability, e.g. being able to walk well enough to be able to walk to community venues to engage in social and leisure activities. Previous work has shown that walking performance such as speed, capacity, and stairs ability are related to free-living physical activity ${ }^{5-7}$. However, what is not known is whether walking performance is related to the type of activity, such as domestic and social activities, undertaken in the community after stroke.

Much of physical therapy after stroke is focused on improving walking performance with the assumption that this will lead to greater independence and participation in community life. An understanding of how walking performance is related to the type of activity undertaken in the community will provide guidance for therapists in planning for the needs of people with stroke post-rehabilitation. Therefore, the specific research question was:

Are the types of community activities performed by individuals who have suffered a stroke correlated with measures of walking performance (speed, automaticity, capacity, stairs ability)?

We therefore carried out a detailed observation on a subset of the cohort of people with stroke for whom we had previously measured walking performance and physical activity using an activity monitor ${ }^{5}$. If walking performance is related to the activities underpinning community participation, therapists can use this information to individually tailor post-rehabilitation community services. For example, those with reasonable walking performance should be encouraged to pursue active leisure and become lifelong exercisers, whereas those with severely limited walking performance may have to take advantage of the advances in rehabilitation technologies and utilize scooters or other transport devices to access and participate in community life.

\section{Methods :::}

\section{Design}

A cross-sectional observational study was conducted in the community in a metropolitan city. This study was conducted over two days. Walking performance was measured on the first day in our laboratory; and observation of activity was carried out on the second day in the community. The two days were not necessarily consecutive but were completed within a twoweek period. For the observation, days of the week were counterbalanced so that data was collected from two participants on each day of the week. Then, the observation period was randomized to be a morning or an afternoon. If the allocated time for observation was in the morning, the examiner went to the participant's home and started recording community activities 30 minutes after the participant's waking up time. If the allocated time for observation was in the afternoon, the examiner went to participant's home and started recording community activities at least five hours before the participants went to bed. Ethical approval was obtained from the Human Research Ethics Committee at the University of Sydney, Sydney, NSW, Australia (Ref No.: 07-2006/9261).

\section{Participants}

People with stroke were recruited from the local community, including stroke clubs. They were included if they were over 50 years old, within 1 to 5 years of their first stroke, and able to walk $10 \mathrm{~m}$ independently without aids or orthoses. They were excluded if they could not speak English, or if they were aphasic and unable to follow instructions. The sample of 14 was a subset of a larger study with 42 participants. The first fourteen subjects who accepted an invitation to participate in this additional study were included. This sample was representative of the main cohort sample $(n=42)$ as they had almost the same mean walking performance. Informed consent was obtained from all participants before data collection commenced. 


\section{Outcome measures}

\section{Demographics}

Age, gender, side of hemiplegia, time since stroke, and presence of spouse were collected.

\section{Walking performance}

Four aspects of walking performance were measured: walking speed, walking automaticity, walking capacity, and stairs ability. The examiner stood close and behind participants and maintained this position throughout all measures to ensure their safety.

Walking speed was measured using the 10-m Walk Test in meters per seconds $(\mathrm{m} / \mathrm{s})^{8}$. Participants were asked to walk 10 meters on the level with their shoes off, without using any aid, and at their comfortable speed. There were two meters before reaching the starting line to allow for acceleration to take place and two meters beyond the finishing line to ensure that walking speed did not slow before reaching 10 meters. Participants performed this test twice and their scores were averaged and used for analysis.

Walking automaticity was measured as the ability to walk under dual and triple task conditions compared with comfortable speed. Participants were asked to walk 10 meters as previously under three additional conditions. The first condition was walking during a concurrent manual task (dual-manual) in which participants were required to walk while carrying (using their intact hand) a polystyrene cup of water, filled to within $7 \mathrm{~mm}$ of the top without spilling the water'. The second condition was walking during a concurrent cognitive task (dualcognitive) in which participants were required to give a correct verbal response on hearing an verbal stimulus: "yes" when they heard the word "red", and "no" when they heard the word "blue". The stimuli were presented using a cassette recorder at three-second intervals in random order to prevent anticipation ${ }^{10}$. The third condition was walking during both tasks (triple) in which participants were required to perform both the manual and cognitive task without spilling the water in the dual-manual task, and making no errors in the dual-cognitive task ${ }^{9}$. In order to detect the decrement of walking speed under the aforementioned conditions, the average speed of walking under the three conditions as a percentage (\%) of participants' comfortable walking speed was calculated.

Walking capacity was measured using the 6-min Walk Test in meters, according to the protocol recommended by the American Thoracic Society ${ }^{11}$. A 40-m corridor was used, and participants were allowed to use their preferred aid. Distance walked in meters, aids used, and resting time were recorded.

Ability to negotiate stairs (stairs ability) was measured using the Timed Up and Down Stairs Test ${ }^{12}$ in stairs per second (stairs/s). There were 11 steps in the flight of stairs, and each step was $140 \mathrm{~cm}$ wide, $17 \mathrm{~cm}$ high, and $30 \mathrm{~cm}$ deep. Participants were asked to stand $30 \mathrm{~cm}$ from the bottom of the first step and to quickly, but safely, go up the stairs, turn around on the top step, and come all the way down until both feet landed on the bottom step (landing). The participants were allowed to choose any method of negotiating the stairs including using the handrails. The time in seconds from the "go" cue until the second foot returned to the bottom landing was measured using a stopwatch and reported as stairs/s.

\section{Community activity}

Community activity was observed using a behavior stream ${ }^{13,14}$. Before each observation session, the examiner asked the participant to carry out his or her routine activities as if the examiner was not present. Every time the participant changed his or her activity, the examiner recorded the time and the nature of the activity (see Table 1 for an example).

The challenge for observational studies using behavior streaming is to reduce the data into meaningful parts in order to analyze it and answer the research question. In the current study, all activities observed in the community were categorized into four types: domestic intrinsic (i.e. personal activities of daily living); domestic extrinsic (i.e. domestic activities at home and around the home); leisure without contact (i.e. activities that were carried out without contact with others); and leisure with contact (i.e. activities that were carried out with contact with others) by two researchers blinded to participants' walking performance. The categories were based on the definitions of De Wit et al. ${ }^{4}$, however their category of leisure and workrelated activities was further divided into those with and those without contact. See Table 2 for community activities observed

Table 1. Example of a behavior stream. X is a 73-year-old lady who lived with her husband. This segment of $1 \mathrm{hr} 41 \mathrm{~min}$ would be categorized as 19 min of domestic intrinsic activities, 3 min of leisure with contact activities and 79 min of leisure without contact activities.

\begin{tabular}{|c|c|}
\hline Time & Activity \\
\hline $2: 55 \mathrm{pm}$ & $\begin{array}{l}\text { Husband opened the door while } X \text { was sitting in the lounge } \\
\text { room watching TV and doing stretching exercises for } \\
\text { shoulders using stick. }\end{array}$ \\
\hline $2: 59$ & X stood up and did pendulum exercises. \\
\hline 3:00 & $\begin{array}{l}\text { X walked a few steps to kitchen door and did shoulder } \\
\text { exercises using theraband. }\end{array}$ \\
\hline 3:07 & $\mathrm{X}$ came back to lounge room and sat watching TV. \\
\hline $3: 59$ & X started stretching exercises for shoulders using stick. \\
\hline 4:01 & X stopped exercises and talked to her husband. \\
\hline 4:04 & $X$ watched TV again. \\
\hline $4: 17$ & Husband brought her food and X started eating. \\
\hline $4: 36$ & $\begin{array}{l}\text { X finished her meal and stood up and walked to kitchen } \\
\text { carrying her plate. }\end{array}$ \\
\hline
\end{tabular}


Table 2. Community activity grouped into four types.

\begin{tabular}{ll}
\hline Type & Activity \\
\hline Domestic intrinsic & Toileting \\
\cline { 2 - 2 } Dressing \\
\hline Washing \\
\hline Eating \\
\hline Sleeping \\
\hline Food preparation \\
\hline Washing up \\
\hline Ironing \\
\hline Gardening \\
\hline Going to mailbox \\
\hline Care of fireplace \\
\hline Eeisure without contact & Exercises inside the house \\
\hline Reading \\
\hline Writing \\
\hline Watching TV \\
\hline Using Computer (typing) \\
\hline Smoking \\
\hline Knitting \\
\hline Exercises outside the house \\
\hline Talking to spouse \\
\hline Phone Calls \\
\hline Visiting \\
\hline Shopping \\
\hline Playing bowls \\
\hline
\end{tabular}

Table 3. Characteristics of participants.

\begin{tabular}{|c|c|}
\hline Characteristic & $\begin{array}{c}\text { Participants } \\
n=14\end{array}$ \\
\hline \multicolumn{2}{|l|}{ Demographics } \\
\hline Age (yr), mean (SD) & $74(10)$ \\
\hline Gender, number of male (\%) & $9(64)$ \\
\hline Side of hemiplegia, number of right side (\%) & $10(71)$ \\
\hline Time since stroke (yr), mean (SD) & $2.5(1.2)$ \\
\hline Lived with spouse, number (\%) & $9(64)$ \\
\hline \multicolumn{2}{|l|}{ Walking performance, mean (SD, range) } \\
\hline Speed (m/s) & $0.89(0.33,0.27-1.40)$ * \\
\hline Automaticity (\%) & $68(13,48-88) \bullet$ \\
\hline Capacity (m) & $350.5(112.6,83-466)$ \\
\hline Stairs ability (stairs/s) & $0.85(0.47,0.19-1.50)$ • \\
\hline \multicolumn{2}{|l|}{ Community activity (min), mean (SD, range) } \\
\hline Domestic intrinsic & $56(25,23-101)$ \\
\hline Domestic extrinsic & $37(42,0-126)$ \\
\hline Leisure without contact & $123(71,35-239)$ \\
\hline Leisure with contact & $39(44,0-125)$ \\
\hline Doing something & $255(35,156-297)$ \\
\hline
\end{tabular}

in the current study. Social interaction such as visits and phone calls ${ }^{15}$ were included as leisure activities with contact.

For each participant, activities were assigned a type, and then the time (min) spent in each type of activity was calculated. Given that the observation time varied slightly between five and six hours across participants, the time spent in activity for each participant was standardized to five hours (300 min). In order to ascertain the total time spent undertaking everyday activities, the time spent in the four types was summed to provide an additional category: "doing something".

\section{Data analysis}

Shapiro-Wilk normality tests determined that the data was normally distributed except for domestic extrinsic and leisure with contact activities, which had negatively skewed data. However, both Pearson's and Spearman's correlation coefficients yielded the same results; therefore Pearson's correlation coefficient is presented for easier interpretation of the data. Statistica computer software was used for data analysis. The level of significance was set at $\mathrm{p}<0.05$.

\section{Results $: \because$.}

\section{Demographics}

Fourteen participants aged 74 years (SD 10) were observed in the community. More than half of the participants were male (64\%), and the majority were right hemiplegics (71\%). Nine participants (64\%) lived with their spouses. All participants were within one to three and a half years after their stroke (see Table 3 for demographics of participants).

\section{Walking performance}

Walking performance is presented in Table 3. Walking speed ranged between $0.3-1.4 \mathrm{~m} / \mathrm{s}$ with five participants walking faster than $1 \mathrm{~m} / \mathrm{s}$. Walking automaticity ranged between 48-88\% of their comfortable speed. Walking capacity over six minutes ranged between $83 \mathrm{~m}$ and $466 \mathrm{~m}$, four participants used a stick, and no participants rested. Stairs ability ranged between 0.19-1.50 stairs/s with most participants using handrails.

\section{Community activity}

All participants were engaged in activity for a considerable proportion of the observation period. On average, participants spent $255 \mathrm{~min}$ (85\%) doing something which left 45 min doing nothing (Table 3). 
On average, the most time spent was in leisure without contact, ranging from 35 to 239 min (mean $123 \mathrm{~min}$ ). While all participants undertook domestic intrinsic activity (mean 56 min), most participants $(\mathrm{n}=10,71 \%)$ undertook leisure with contact activity (mean $39 \mathrm{~min}$ ) even though, for two of these, it was for less than 5 min. Most participants $(n=11$, $79 \%$ ) also carried out domestic extrinsic activities even though, for three of these participants, it was for no more than five minutes.

\section{Relationship between walking performance and community activity}

The correlation between walking performance and the amount and type of community activity is presented in Table 4. There was no relationship between any aspect of walking performance and the total time spent by participants doing something, i.e. carrying out all types of community activity.

No aspect of walking performance was correlated with domestic intrinsic activity. Walking speed and stairs ability were significantly correlated with leisure with contact activity $(\mathrm{r}=0.56, \mathrm{p}=0.04$, and $\mathrm{r}=0.57, \mathrm{p}=0.03$ respectively $)$ and inversely correlated with leisure without contact $(\mathrm{r}=-0.72, \mathrm{p}<0.01$, and $\mathrm{r}=-0.66, \mathrm{p}=0.01$ respectively). Walking capacity was also inversely correlated with leisure without contact $(\mathrm{r}=-0.77, \mathrm{p}<0.01)$. Only stairs ability was significantly correlated with domestic extrinsic activity $(\mathrm{r}=0.77, \mathrm{p}<0.01)$.

\section{Discussion $: \therefore$.}

In this group of people with stroke who could walk and use stairs, walking performance was not related to the overall amount of activity that was carried out in the community nor domestic intrinsic activities. All walking performance measures except automaticity were inversely related to leisure activities that were carried out without social contact, which were mainly passive activities such as reading and watching TV. Walking speed and stairs ability were significantly related to leisure activities that were carried out with social contact, such as exercises outside the house and playing bowls. Stairs ability was the only measure significantly related to domestic extrinsic activities that were carried out at home and around the home, such as food preparation and gardening. However, examination of the correlation matrix suggests all measures of walking performance excepted automaticity are related to domestic extrinsic and leisure with contact activities and inversely correlated with leisure without contact activities. Given the correlations are either significant or with a $p<0.1$, we contend that, considering the compromised power because of the small sample size, the best interpretation is that all measures of walking performance except automaticity are related to these three types of activities.

It is not surprising that individuals after stroke were engaged in some activity for a large proportion of the observation period, because humans are goal-directed and all purposeful activity was recorded regardless of the physical requirements of the activity. Although in the current study we purposely classified activities carried out in the community based on the nature of the activity, the fact that walking performance was correlated with the type of activity suggests that the physical requirements of some types of activities are important.

The failure of walking performance to correlate with the amount of time spent in domestic intrinsic activity may be because all participants carried out this type of activity and all participants could walk and lived at home without formal community support. In more supported environments, such as nursing homes and hostels, walking performance may correlate with domestic intrinsic activity.

All aspects of walking performance, except for automaticity, were correlated with the ability to carry out domestic extrinsic activity. Such a relationship is perhaps not surprising given the physical requirements of this type of activity. Activities such as gardening and going to the mailbox require

Table 4. Correlation between walking performance and amount and type of community activity using Pearson's correlation coefficient.

\begin{tabular}{|c|c|c|c|c|c|}
\hline \multirow{3}{*}{ Walking performance } & \multirow[b]{3}{*}{ Doing something } & \multicolumn{4}{|c|}{ Community activity } \\
\hline & & \multicolumn{4}{|c|}{ Type } \\
\hline & & Domestic intrinsic & Domestic extrinsic & Leisure without contact & Leisure with contact \\
\hline \multirow[t]{2}{*}{ Speed (m/s) } & $r=-0.05$ & $\mathrm{r}=0.14$ & $\mathrm{r}=0.51$ & $\mathrm{r}=-0.72$ & $r=0.56$ \\
\hline & $p=0.86$ & $p=0.63$ & $p=0.06$ & $p<0.01$ & $p=0.04$ \\
\hline \multirow[t]{2}{*}{ Automaticity (\%) } & $r=-0.06$ & $r=-0.21$ & $r=0.35$ & $r=-0.02$ & $r=-0.22$ \\
\hline & $p=0.85$ & $p=0.47$ & $p=0.23$ & $p=0.94$ & $p=0.45$ \\
\hline \multirow[t]{2}{*}{ Capacity (m) } & $\mathrm{r}=-0.28$ & $r=0.14$ & $\mathrm{r}=0.47$ & $\mathrm{r}=-0.77$ & $r=0.49$ \\
\hline & $p=0.34$ & $p=0.64$ & $p=0.09$ & $p<0.01$ & $p=0.07$ \\
\hline \multirow[t]{2}{*}{ Stairs ability (stair/s) } & $r=0.26$ & $r=-0.05$ & $\mathrm{r}=0.77$ & $r=-0.66$ & $r=0.57$ \\
\hline & $p=0.38$ & $p=0.86$ & $p<0.01$ & $p=0.01$ & $p=0.03$ \\
\hline
\end{tabular}


participants to leave the house, and therefore a good walking speed, capacity, and stairs ability are likely to make undertaking these activities easier. Moreover, better walking performance correlated with leisure with contact. Given four of the six activities in this type required leaving the home, this will obviously be easier if walking speed, capacity, and stairs ability is good.

Our results showed that the highest correlation for domestic extrinsic and leisure with contact activities was with stairs ability, in similarity to the findings of our previous work. Alzahrani, Dean and $\mathrm{Ada}^{5}$ found that ability to negotiate stairs was the best predictor of free-living physical activity that was measured using an activity monitor. This result is not surprising given that stairs provide an environmental barrier to physical activity. There is evidence that people without disability take the stairs more often than those with disability, who were more likely to take elevators and avoid obstacles $^{16}$

In support of the notion that the physical requirements of tasks are important to consider even when determining the type of activity undertaken, a negative correlation was found between walking performance (mainly speed, capacity, and stairs ability) and leisure without contact activities. Activities observed in this type were largely passive, e.g. watching TV, reading, etc. Moreover, exercises inside the house were carried out while sitting and were confined to stretching of the upper and lower extremities.

Findings in this study have implications for rehabilitation of people with stroke. First, community activity and social interaction may be increased if attention is paid to improving walking performance (particularly walking speed, capacity, and stairs ability) during rehabilitation after stroke. Second, depending on their walking performance, therapists can tailor community services. People with stroke who obtain reasonable walking performance should be encouraged to participate in ongoing exercise classes in the community, whereas poor walkers may need to be provided with scooters or wheelchairs to maximise their opportunity to pursue activities outside the house. Third, given most leisure activities were undertaken without contact, individuals after stroke may also benefit from specific intervention to enhance leisure activities within the home. Nour et al. ${ }^{17}$ randomized clinical trial revealed that people who received a home leisure educational program increased leisure activities and community activity as a whole, e.g. they carried out home activities more often and were more willing to resume community-based activities (bowling, shopping, association activities, etc.) than a placebo. Fourth, individuals may also benefit from being referred to community groups that provide regular phone contact. This strategy would help to avoid social isolation and increase the amount of time spent in leisure activities with contact regardless of walking performance.

The findings of this study should be considered with caution as it has some limitations. First, the sample size was small, which may have reduced the strength of the correlations obtained. Second, findings of this study are from relatively high-functioning people with stroke residing in the community and may not apply to those with severe walking limitations. This group of community-dwelling people with stroke could all walk and use stairs although with varying levels of performance. On average, walking speed ${ }^{18}$, automaticity ${ }^{19}$, capacity ${ }^{20}$, and ability to use stairs ${ }^{21}$ was about three-quarters of normal elderly performance. Third, there are other factors that may correlate with community activity of this population.

\section{Conclusion $::$.}

In conclusion, the type of activity that is carried out in the community by people with stroke is correlated with their walking performance. This suggests that, if walking performance (particularly walking speed, capacity, and stairs ability) is poor after stroke, community activity may be limited whereby people may become housebound and isolated from society. The prescription of ongoing services to promote community participation could, therefore, be based on walking performance.

\section{Acknowledgements : $:$.}

We would like to thank the King Faisal University in the Kingdom of Saudi Arabia for financial support of Matar's doctoral studies. In addition, we would like to thank Simone Dorsch for her help in walking performance tests and Gemma Lloyd for her help in recruiting participants. 


\section{References $: \because$.}

1. Desrosiers J, Rochette A, Noreau L, Bourbonnais D, Bravo G, Bourget A. Long-term changes in participation after stroke. Top. 2006;13(4):86-96.

2. Mayo NE, Wood-Dauphinee S, Côté R, Durcan L, Carlton J. Activity, participation, and quality of life 6 months poststroke. Arch Phys Med Rehabil. 2002;83(8):1035-42.

3. Carod-Artal FJ, Gonzalez-Gutiérrez JL, Herrero JA, Horan T, De Seijas EV. Functional recovery and instrumental activities of daily living: follow-up 1-year after treatment in a stroke unit. Brain Inj. 2002;16(3):207-16

4. De Wit L, Kamsteegt H, Yadav B, Verheyden G, Feys H, De Weerdt W. Defining the content of individual physiotherapy and occupational therapy sessions for stroke patients in an inpatient rehabilitation setting. Development, validation and inter-rater reliability of a scoring list. Clin Rehabil. 2007;21(5):450-9.

5. Alzahrani MA, Dean CM, Ada L. Ability to negotiate stairs predicts free-living physical activity in community-dwelling people with stroke: an observational study. Aust J Physiother. 2009;55(4):277-81.

6. Rand D, Eng JJ, Tang PF, Jeng JS, Hung C. How active are people with stroke?: use of accelerometers to assess physical activity. Stroke. 2009;40(1):163-8.

7. Alexander NB, Guire KE, Thelen DG, Ashton-Miller JA, Schultz AB, Grunawalt JC, et al. Selfreported walking ability predicts functional mobility performance in frail older adults. J Am Geriatr Soc. 2000;48(11):1408-13.

8. Wade D. Measurement in neurological rehabilitation. Oxford: Oxford University Press; 1992.

9. Canning CG, Ada L, Paul SS. Is automaticity of walking regained after stroke? Disabil Rehabil. 2006;28(2):97-102.

10. Bowen A, Wenman R, Mickelborough J, Foster J, Hill E, Tallis R. Dual-task effects of talking while walking on velocity and balance following a stroke. Age Ageing. 2001;30(4):319-23.

11. ATS. ATS statement: guidelines for the six-minute walk test. Am J Respir Crit Care Med. 2002;166(1):111-7.
12. Flansbjer UB, Holmbäck AM, Downham D, Patten C, Lexell J. Reliability of gait performance tests in men and women with hemiparesis after stroke. J Rehabil Med. 2005;37(2): 75-82.

13. VanHaitsma K, Lawton MP, Kleban MH, Klapper J, Corn J. Methodological aspects of the study of streams of behavior in elders with dementing illness. Alzheimer Dis Assoc Disord 1997;11(4):228-38

14. Bernhardt J, Dewey H, Thrift A, Donnan G. Inactive and alone: physical activity within the first 14 days of acute stroke unit care. Stroke. 2004;35(4):1005-9.

15. Boden-Albala B, Litwak E, Elkind MS, Rundek T, Sacco RL. Social isolation and outcomes post stroke. Neurology. 2005;64(11):1888-92.

16. Shumway-Cook A, Patla AE, Stewart A, Ferrucci L, Ciol MA, Guralnik JM. Environmental demands associated with community mobility in older adults with and without mobility disabilities. Phys Ther. 2002;82(7):670-81.

17. Nour K, Desrosiers J, Gauthier P, Carbonneau H. Impact of a home leisure educational program for older adults who have had a stroke (Home Leisure Educational Program). Ther Recreation J. 2002;36(1):48-64.

18. Bohannon RW. Comfortable and maximum walking speed of adults aged 20-79 years: reference values and determinants. Age Ageing. 1997;26(1):15-9.

19. Paul SS, Ada L, Canning CG. Automaticity of walking -- implications for physiotherapy practice Physical Therapy Reviews. 2005;10(1):15-23.

20. Enright PL, Sherrill DL. Reference equations for the six-minute walk in healthy adults. Am J Respir Crit Care Med. 1998;158(5 Pt 1):1384-7.

21. Clémençon M, Hautier CA, Rahmani A, Cornu C, Bonnefoy M. Potential role of optimal velocity as a qualitative factor of physical functional performance in women aged 72 to 96 years. Arch Phys Med Rehabil. 2008;89(8):1594-9. 